\title{
Assessment of Indoor Air Quality in Otorhinolaryngology Clinics
}

\author{
Kang Hyun Lee and Dong-Kyu Kim \\ Department of Otorhinolaryngology-Head and Neck Surgery, Chuncheon Sacred Heart Hospital, Hallym University College of Medicine, \\ Chuncheon, Korea
}

이비인후과 진료실의 실내공기질 분석

이강현 · 김동규

한림대학교 의과대학 춘천성심병원 이비인후-두경부외과학교실

\author{
Received November 15, 2019 \\ Revised April 10,2020 \\ Accepted April 16, 2020 \\ Address for correspondence \\ Dong-Kyu Kim, MD, PhD \\ Department of Otorhinolaryngology- \\ Head and Neck Surgery, \\ Chuncheon Sacred Heart Hospital, \\ Hallym University \\ College of Medicine, \\ 77 Sakju-ro, \\ Chuncheon 24253, Korea \\ Tel $+82-33-240-5180$ \\ Fax +82-33-241-2909
}

E-mail doctordk@naver.com
Background and Objectives Otorhinolaryngology clinics are frequently exposed to various air pollutants. This can have a potentially harmful effect on the health of the healthcare personnel. However, there is still a lack of studies on the assessment of indoor air quality in otorhinolaryngology clinics. Therefore, this study aimed to measure indoor air quality in otorhinolaryngology clinics.

Subjects and Method In this study, we prospectively measured indoor air quality indices [particulate matter (PM), carbon dioxide $\left(\mathrm{CO}_{2}\right)$, total volatile organic compounds (VOCs), PM2.5, Nitrogen dioxide $\left(\mathrm{NO}_{2}\right)$, carbon monoxide $(\mathrm{CO})$, and ozone] using portable passive air quality monitoring sensors in otorhinolaryngology clinics.

Results The mean concentrations of $\mathrm{PM}, \mathrm{CO}_{2}, \mathrm{VOCs}$, and $\mathrm{NO}_{2}$ were significantly higher during office hours than after; however, there was no significant differences in $\mathrm{CO}$ and ozone concentration between the two time periods. The proportions of tolerable to poor-quality (exceeding acceptable level) levels of $\mathrm{CO}_{2}$, total VOCs, $\mathrm{NO}_{2}$ was $25 \%, 25 \%, 12.5 \%$ during office hours, respectively. On the other hand, there was no proportion of tolerable to poor-quality level of PM, CO, ozone during office hours.

Conclusion We found that otorhinolaryngology clinics are easily exposed to ambient indoor air pollution. Therefore, we suggest implement health-related protective strategies for ambient indoor air pollution in otorhinolaryngology clinics may be needed for healthcare personnel. Korean J Otorhinolaryngol-Head Neck Surg 2020;63(10):458-62

Key Words Air pollution · Carbon dioxide · Indoor air quality · Nitrogen dioxide · Particulate matter · Volatile organic compounds.

\section{서 론}

오늘날 도시에 거주하는 사람들은 하루 중 거의 대부분을 실내공간에서 활동하고 있다. 그런데 실내공기질은 실외와는 달리 실내의 오염원과 실외 오염물질의 유입에 의해 실내공기

This is an Open Access article distributed under the terms of the Creative Commons Attribution Non-Commercial License (https://creativecommons.org/licenses/by-nc/4.0) which permits unrestricted non-commercial use, distribution, and reproduction in any medium, provided the original work is properly cited.
오염이 발생할 경우 쉽게 정화되지 않는 특성을 지닌다. 건물 내 거주자들이 일시적 또는 만성적인 두통, 눈, 코와 목의 따 가움, 마른기침, 피부 건조 및 가려움 등의 증상을 호소하는 빌딩증후군(Sick Building Syndrome)이 대표적인 실내공기 오염의 사례이다. ${ }^{1-3)}$ 그러므로 실내공기질에 대한 명확한 평 가와 오염을 방지할 수 있는 적절한 대책을 수립하는 것은 현대인의 건강에 있어서 매우 중요하다.

실내공기질 오염물질은 크게 입자상 물질, 가스상 물질, 병 
원성으로 구별할 수 있는데, 입자상 물질로는 미세먼지(PM10), 초미세먼지(PM2.5), 석면(asbestos) 등이 있으며, 가스상 물질 로는 일산화탄소 $(\mathrm{CO})$, 이산화질소 $\left(\mathrm{NO}_{2}\right)$ 를 비롯하여 휘발성 유기화합물(VOCs), 포름알데하이드( $\mathrm{HCHO})$, 라돈(Rn), 오 존 $\left(\mathrm{O}_{3}\right)$, 그리고 병원성 세균(microbe)으로는 실내 공기 중에 부유하는 총부유세균이 있다. ${ }^{4-7)}$ 그리고 연소과정, 호흡, 실내 에서의 흡연, 오염된 외부 공기의 실내유입, 건물의 페인트, 벽 지, 단열재, 합판, 접착제 등 건축자재물이 실내공기 오염물질 의 주요 발생원에 해당된다.8)

국내에서는 실내공기질 관리법에 따라 10 가지 실내오염물 질 관리기준을 설정하고 이를 바탕으로 다중이용시설의 실 내공기질을 관리하는데 이는 유지기준 5항목(미세먼지, 이산 화탄소, 포름알데하이드, 총부유세균, 일산화탄소)과 권고기 준 5항목(이산화질소, 라돈, 휘발성유기화합물, 초미세먼지, 곰팡이)으로 이루어져 있다. ${ }^{9)}$ 그리고 유지기준 항목은 1년에 1 번, 권고기준 항목은 2 년에 1 번 측정하여야 하며, 유지기준 을 초과한 경우 과태료를 부과받을 수 있다. 게다가 2019년 7월 1일부터 어린이집, 노인요양시설, 산후조리원, 의료기관 등 민감계층이 이용하는 민감시설에서는 미세먼지, 초미세먼 지, 포름알데하이드, 라돈의 관리기준이 대폭 강화되었다.

한편, 국내에서는 학교 및 유치원 같은 교육시설이나 사무 실 혹은 일반 주택 공간에서의 실내공기 오염에 대한 실태조 사가 활발히 이루어지고 있으나, 진료실에 대한 실내공기질 연구사례는 매우 부족한 실정이다. ${ }^{10-13)}$ 의료인의 경우 실내공 간 중 진료실이라는 특수한 공간에서 근무시간 대부분을 소 비하고 활동하는 것을 고려한다면, 진료실에 대한 실내공기 질의 구체적인 실태조사가 필요하다. 그러므로 저자들은 본 연구에서 이비인후과 진료실에서 실내공기 질을 측정하여 이 비인후과 진료실의 실내공기 오염에 대한 분석을 하였다.

\section{대상 및 방법}

\section{연구 방법}

본 연구는 한림대학교 춘천성심병원 임상윤리심의 위원회 승인(NON2019-001) 후에 전향적인 방법으로 수행되었다. 실내공기 오염물질 모니터링을 위한 용도로 검증된 공기 샘플 링 장치인 uHoo 필터(CuHoo Limited, Kwun Tong, Hong Kong)를 구입하여 이비인후과 진료실에 설치해 실내공기질 평가를 수행하였다. uHoo 필터는 총 9센서로 이루어져 있으 며, 이는 미국 환경 보호국(United States Environmental Protection Agenc)과 세계 보건기구(World Health Organization)가 지정한 안전 임계 값을 사용하였다. ${ }^{13)}$ 본 연구에서 우리는 9개의 센서를 통해 대기 온도, 대기 압력, 대기 습도의
정보를 얻었으며, 미세먼지, 이산화탄소, 휘발성유기화합물, 이산화질소, 일산화탄소, 오존으로 이루어진 6개의 실내공기 오염물질 농도를 각각 측정하였다. 측정 시간은 2019년 2월 6월까지 총 5개월 동안 24시간 지속적으로 시행하였고 정확 한 실내공기 오염의 정도를 파악하기 위해서 진료실 내의 공 기청정기 사용을 금하였으며, 진료실의 환기는 특정시간(12 13시 및 17 18시)에만 이루어졌다. 본 연구가 진행된 진료실 은 비과 진료만 이루어지는 진료실로 한정하였으며, 진료 시 간(during office time)의 정의는 9 12시까지와 14 17시까지 로 정의하였고, 진료외 시간(after office time)의 정의는 20시 부터 그 다음날 5 시까지로 정의하였다. 실내공기 오염물질 농 도는 1 분 간격으로 샘플링 장치에서 측정되었으며, 결과값은 진료 시간 및 진료 외 시간으로 구별하여 매일의 평균 농도를 구하고 이를 중위값과 범위로 표현하였다. 모든 통계 분석은 SPSS statistics version 21.0(IBM Corp., Armonk, NY, $\mathrm{USA}$ )를 사용하였고, $p<0.05$ 일시 통계적으로 유의성을 가지 는 것으로 판단하였다.

\section{결 과}

본 연구에서 2 6월까지 측정된 데이터 중 토요일, 일요일 및 공휴일 등 진료가 없는 날은 제외한 후에 실내공기 오염물 질의 진료 시간 및 진료 외 시간의 평균 농도를 비교하였다. 본 연구에서 사용된 6 개의 실내공기 오염물질 농도를 각각 acceptable range, tolerable range, poor quality range로 구 분하여 실내공기질을 평가하였고, tolerable range는 장기간 노출되면 건강에 위해한 농도를 의미하며 poor quality range 는 해당 농도에 노출되지 말 것을 권하는 농도를 의미한다. 각각의 기준 범위는 Table 1 과 같다.

각각의 실내공기 오염물질의 평균 농도를 진료 시간 여부 에 따라 비교할 시에 미세먼지 평균 농도의 중위값은 진료 시간은 $15.1(7.8 \sim 33.2) \mathrm{mg} / \mathrm{m}^{3}$, 진료 외 시간은 10.1(7.3 14.5) $\mathrm{mg} / \mathrm{m}^{3}$ 였으며, 이산화탄소 평균 농도의 중위값은 진료 시간 은 593.1(400 1645.9) ppm, 진료 외 시간은 455.5(422 644.4) $\mathrm{ppm}$ 으로 통계학적으로 의미있게 진료 시간에 미세먼지와 이 산화탄소 농도가 증가하는 것을 관찰할 수 있었다(Table 2). 게다가, 휘발성유기화합물의 진료 시간 및 진료 외 시간 평균 농도 중위값이 각각 142.4(11.7 1054.1) ppb, 15.5(5 75.1) $\mathrm{ppb}$ 였고 이산화질소의 진료 시간 및 진료 외 시간 평균 농도 는 중위값이 각각 71.7(0.4 174.7) ppb, 3.6(0.4 44.6) ppb로 통계학적으로 의미있게 진료 시간에 농도가 증가하는 것을 관찰할 수 있었다(Table 2). 반면에 일산화탄소와 오존의 평 균 농도 중위값은 진료 시간 및 진료 외 시간에서 통계학적 
Table 1. Reference range of air quality indices used in this study

\begin{tabular}{lccc}
\hline $\begin{array}{c}\text { Air quality } \\
\text { indices }\end{array}$ & $\begin{array}{c}\text { Acceptable } \\
\text { range }\end{array}$ & $\begin{array}{c}\text { Tolerable } \\
\text { range }\end{array}$ & $\begin{array}{c}\text { Poor quality } \\
\text { range }\end{array}$ \\
\hline $\mathrm{PM}\left(\mathrm{mg} / \mathrm{m}^{3}\right)$ & $<50$ & $50-100$ & $>100$ \\
$\mathrm{CO}_{2}(\mathrm{ppm})$ & $400-800$ & $800-1500$ & $>1500$ \\
$\mathrm{VOCs}(\mathrm{ppb})$ & $0-400$ & $400-800$ & $>800$ \\
$\mathrm{NO}_{2}(\mathrm{ppb})$ & $<100$ & $100-250$ & $>250$ \\
$\mathrm{CO}(\mathrm{ppm})$ & $<35$ & $35-70$ & $>70$ \\
$\mathrm{O}_{3}(\mathrm{ppb})$ & $<30$ & $30-70$ & $>70$
\end{tabular}

PM: particulate matter, $\mathrm{CO}_{2}$ : carbon dioxide, vOCs: total volatile organic compounds, $\mathrm{NO}_{2}$ : Nitrogen dioxide, $\mathrm{CO}$ : carbon monoxide, $\mathrm{O}_{3}$ : ozone

Table 2. Comparison of the concentration of each air quality index between during office hour and after office hour

\begin{tabular}{lccc}
\hline $\begin{array}{c}\text { Air quality } \\
\text { indices }\end{array}$ & $\begin{array}{c}\text { During office hour } \\
\text { (median, range) }\end{array}$ & $\begin{array}{c}\text { After office hour } \\
\text { (median, range) }\end{array}$ & p value \\
\hline $\mathrm{PM}\left(\mathrm{mg} / \mathrm{m}^{3}\right)$ & $15.1(7.8-33.2)$ & $10.1(7.3-14.5)$ & $<0.001$ \\
$\mathrm{CO}_{2}(\mathrm{ppm})$ & $593.1(400-1645.9)$ & $455.5(422-644.4)$ & $<0.001$ \\
$\mathrm{VOCs}(\mathrm{ppb})$ & $142.4(11.7-1054.1)$ & $15.5(5-75.1)$ & $<0.001$ \\
$\mathrm{NO}_{2}(\mathrm{ppb})$ & $71.7(0.4-174.7)$ & $3.6(0.4-44.6)$ & 0.012 \\
$\mathrm{CO}(\mathrm{ppm})$ & 0 & 0 & $*$ \\
$\mathrm{O}_{3}(\mathrm{ppb})$ & $2.3(1.6-4.6)$ & $2.4 .(1.7-5.0)$ & 0.430 \\
\hline
\end{tabular}

*cannot be computed because the standard deviation of both group are zero. PM: particulate matter, $\mathrm{CO}_{2}$ : carbon dioxide, VOCs: total volatile organic compounds, $\mathrm{NO}_{2}$ : Nitrogen dioxide, $\mathrm{CO}$ : carbon monoxide, $\mathrm{O}_{3}$ : ozone

으로 의미있는 농도 차이를 관찰할 수 없었다(Table 2).

한편, 6개의 실내공기 오염물질 농도를 acceptable range, tolerable range, poor quality range로 구분하는 경우 이산 화탄소, 휘발성유기화합물, 이산화질소의 농도가 진료 시간 에 $12.5 \%$ 이상 acceptable range을 벗어난 범위의 값이 측정 되었으며, 이산화탄소 및 휘발성유기화합물의 경우 각각 12.5\%에서 poor quality range로 측정되었다(Table 3). 그러 나 미세먼지의 경우 평균 농도는 진료 시간이 높았으나 $\mathrm{ac}^{-}$ ceptable range를 넘어가는 경우는 관찰되지 않았다.

\section{고 찰}

여러 가지 종류의 대기오염 노출과 심혈관, 호흡기 및 신경 계 질환 또는 암을 포함한 다양한 질환 사이의 인과관계는 이 미 잘 알려져 있다. 최근에는 주택, 학교, 사무실, 공공건물 등 오염되는 실내공간의 공기가 실내거주자들의 건강에 나쁜 영 향을 미치고 있음이 밝혀지고 있다. ${ }^{14-16)}$ 따라서 일상생활 중 대부분의 시간이 다양한 형태의 실내공간에서 이루어지는 오 늘날, 실내공기질의 유해 환경에 대한 실태조사는 매우 중요 하다. 특히, 병원에서 이비인후과 진료실은 일반병동 및 다른 임상진료과 진료실과 비교할 때 실내공기질 오염물질 노출이
Table 3. Proportion of unacceptable quality level of air quality indices in clinic

\begin{tabular}{|c|c|c|c|}
\hline $\begin{array}{l}\text { Air quality } \\
\text { indices }\end{array}$ & $\begin{array}{c}\text { Acceptable } \\
\text { range }(\%)\end{array}$ & $\begin{array}{l}\text { Tolerable } \\
\text { range }(\%)\end{array}$ & $\begin{array}{c}\text { Poor quality } \\
\text { range }(\%)\end{array}$ \\
\hline \multicolumn{4}{|l|}{$\overline{P M}$} \\
\hline During office hour & 100 & 0 & 0 \\
\hline After office hour & 100 & 0 & 0 \\
\hline \multicolumn{4}{|l|}{$\mathrm{CO}_{2}$} \\
\hline During office hour & 75 & 12.5 & 12.5 \\
\hline After office hour & 100 & 0 & 0 \\
\hline \multicolumn{4}{|l|}{ VOCs } \\
\hline During office hour & 75 & 12.5 & 12.5 \\
\hline After office hour & 100 & 0 & 0 \\
\hline \multicolumn{4}{|l|}{$\mathrm{NO}_{2}$} \\
\hline During office hour & 87.5 & 12.5 & 0 \\
\hline After office hour & 100 & 0 & 0 \\
\hline \multicolumn{4}{|l|}{$\mathrm{CO}$} \\
\hline During office hour & 100 & 0 & 0 \\
\hline After office hour & 100 & 0 & 0 \\
\hline \multicolumn{4}{|l|}{$\mathrm{O}_{3}$} \\
\hline During office hour & 100 & 0 & 0 \\
\hline After office hour & 100 & 0 & 0 \\
\hline
\end{tabular}

PM: particulate matter, $\mathrm{CO}_{2}$ : carbon dioxide, VOCs: total volatile organic compounds, $\mathrm{NO}_{2}$ : Nitrogen dioxide, $\mathrm{CO}$ : carbon monoxide, $\mathrm{O}_{3}$ : ozone

상대적으로 많은 환경이다. 왜냐하면 환자의 병력청취 및 이 학적 검진 이외에도 이비인후과 진료실에서는 조직검사, 농양 의 절개 및 배농, 출혈 소작, 괴사 및 육아 조직 제거(necrotic and granulation tissue debridement)등 다양한 종류의 처치 (procedure)가 시행되기 때문이다. 그리고 처치에 사용하는 각종 기구들의 소독을 위한 공간도 이비인후과 진료실 내에 존재하는데 이 역시 실내공기질 오염물질의 노출원이 될 수 있다. 게다가 일반적으로 이비인후과 진료실은 외부 소음 차 단 및 환자의 개인 사생활 보호를 위한 목적으로 진료가 진행 되는 동안 외부와의 환기가 차단된 경우가 대부분이고 이는 진료실 실내공기질에 악영향을 미칠 것으로 생각된다. 그러므 로, 대부분의 시간을 이비인후과 진료실에서 보내는 이비인후 과 의사 입장에서 이비인후과 진료실의 실내공기질 조사는 매우 중요한 의미를 지닌다.

실내공기 오염물질 중 미세먼지는 인간 및 동물이 호흡할 때 흡입되어 하기도에 침투할 수 있는데, 특히 입자의 크기가 $2.5 \mu \mathrm{m}$ 이하인 초미세먼지의 경우 상기도 및 기관지에서 걸 러지지 않고 폐포에 쉽게 도달하게 되어 폐질환을 야기하는 것으로 잘 알려져 있다. ${ }^{4,5,17)}$ 미세먼지가 유발하는 질환으로 는 천식이 대표적이며, 이는 기침, 호흡곤란, 흥부 압박감 등 의 증상을 초래하며 환경변화에 민감하게 반응하기 때문에 
대기오염으로 인한 건강피해를 논하는 데 있어 일반적인 환 경보건의 건강지표로 사용된다. ${ }^{18)}$ 또한 이러한 미세먼지는 중금속의 농축과 밀접하게 관련되어 있다. 일반적으로 입자 의 크기가 감소함에 따라 입자의 표면적은 급증하기 때문에, 유해성 가스 및 $\mathrm{Ni}, \mathrm{Cr}, \mathrm{Pb}$ 등과 같은 중금속을 미세먼지가 쉽게 흡착하게 되고 이를 통해서 호흡할 때 인체 안으로 중 금속이 도달하게 되는 것이다. ${ }^{19)}$ 본 연구에서 미세먼지의 농 도는 진료 시간이 진료 외 시간과 비교하여 평균 농도가 유 의미하게 높았다. 미세먼지의 주요 발생원으로는 진료실에서 사용하는 각종 비강 스프레이 및 김서림 방지제 등의 분무 용품, 비강패킹제 및 거즈 등의 모양절단, 냉난방 장치, 그리 고 빈번한 환자의 왕래로 인한 외부 미세먼지 유입 등이 고 려된다. 비록 진료 시간의 미세먼지 평균 농도가 acceptable range에 들어가 있지만, 장시간 그리고 장기간 진료실이라는 특수한 실내공간에서 생활하는 이비인후과 의사 관점에서 볼 때 진료실 내에서 공기청정기 사용 및 처치시에 미세먼지 저감을 위한 노력이 필요할 것으로 생각된다.

이산화탄소는 실내에서는 사람의 호흡과 연료의 연소에 의해 주로 발생되며, 농도가 증가하면 호흡곤란, 두통 등의 증상이 나타난다. 기존 연구에서 500 5000 ppm의 이산화 탄소가 노출 시 심혈관계와 자율신경계에 영향을 미치는 것 으로 밝혀졌다. ${ }^{20-22)}$ 한편, 실내의 휘발성유기화합물의 농도 는 1 2 ppm 이하의 매우 낮은 상태에서도 인체의 건강에 영 향을 미치게 되는데 인체 내의 자극과 증상이 매우 경미하고 서서히 나타나는 것이 특징이다. 휘발성유기화합물 물질은 주로 호흡기 자극과 두통을 유발하는 원인이 되고, 신경생리 학적 기능장애 등을 유발하는 것으로 알려져 있다. ${ }^{23-26)}$ 또한 휘발성유기화합물 물질에 대한 인체의 반응 정도는 개인에 따라 큰 차이를 보인다. ${ }^{23)}$ 본 연구에서 이산화탄소와 휘발성 유기화합물의 농도는 진료 시간이 진료 외 시간과 비교하여 평균 농도가 유의미하게 높았으며, 진료 시간의 평균 농도가 $12.5 \%$ 에서 poor quality range로 측정되었다. 이산화탄소는 사람들의 호흡 이외에도 이비인후과 진료실에서 행하여지는 각종 소작술 시에 발생한다. 한편, 이비인후과 진료실에서 휘 발성유기화합물의 주요 발생원은 의료기구 멸균을 위해 사 용하는 ethylene oxide gas 멸균기 및 조직 검사 시에 사용 하는 포름알데히드 용액이 가장 대표적인 원인일 것으로 추 정된다. 본 연구의 결과를 고려할 때 의료진의 건강을 위해서 진료 시간에 이산화탄소와 휘발성유기화합물의 농도를 낮추 기 위한 장비 교체 및 해당 장비 사용 시 방진 마스크 착용 등 적극적인 개입이 필요할 것으로 생각된다.

대기중의 질소화합물 중 이산화질소는 호흡할 때에 체내 로 침입해서 폐포까지 깊이 도달하여 헤모글로빈의 산소 운
반능력을 저하시키고, 과량의 농도에 노출 시 수 시간 내에 호흡곤란을 수반한 폐수종 염증을 일으키는 독성이 강한 물 질이다. 일반적으로 호흡에 의해 이산화질소 노출농도의 80 90\%가 체내로 흡수될 수 있으며, $2 \mathrm{ppm}$ 이상의 이산화 질소의 농도가 건강한 성인의 폐기능을 악화시킬 수 있다고 알려져 있다. ${ }^{2728)}$ 이산화질소는 고온연소의 부산물로서 실외 에서는 주로 차량, 발전소 및 산업공정에서 주로 발생되며, 실내에서는 가스렌지, 석유난로, 난방기, 흡연 등과 같은 연 소과정에서 발생된다. 본 연구에서는 중앙 공조 시스템으로 작동되기 때문에 냉난방 장치를 통제할 수 없는 한계점을 지 녔으며, 이로 인해 이산화 질소의 농도가 진료 시간이 진료 외 시간과 비교하여 평균 농도가 유의미하게 높고 진료 시간 에 $12.5 \%$ 이상 acceptable range을 벗어난 범위의 값이 측정 된 것으로 생각된다. 그러나 본 연구에서 일산화탄소와 오존 의 경우 진료 시간과 진료 외 시간에 평균 농도의 차이는 없 었으며, 항상 acceptable range에서 농도가 유지되어 비교적 잘 관리가 되고 있는 실내대기 오염물질로 생각된다. 그러나 본 연구는 다음의 제한점을 지니고 있다. 첫째, 다른 임상진 료과 진료실 혹은 대조군(임상진료과 진료실 이외의 병원 내 공간)에서 측정한 실내공기질 자료가 없어 이비인후과 진료 실과 병원 내 다른 장소를 비교한 실내공기 오염의 정도의 차이를 파악할 수 없다. 둘째, 한 의료기관에서만 측정된 수 치이기 때문에 다른 의료기간에서 실내공기질 검증을 위한 추가 연구가 필요하다.

이비인후과 진료실은 다양한 실내공기 오염물질에 노출되 어 있는 공간이다. 본 연구에서는 이비인후과 진료실에서 실 내공기 오염물질 중 미세먼지, 이산화탄소, 휘발성유기화합 물, 이산화질소의 농도가 진료시간에 상대적으로 높게 측정 되는 것을 발견하였다. 일반적으로 이비인후과 의사들이 진 료실에서 부분의 시간을 소비하고 활동하는 것을 고려한다 면, 이에 대한 인식과 개선방향에 대한 연구가 지속적으로 필요하다.

\section{Acknowledgments}

None.

\section{Author Contribution}

Conceptualization: Kang Hyun Lee, Dong-Kyu Kim. Data curation: Kang Hyun Lee. Formal analysis: Dong-Kyu Kim. Investigation: Kang Hyun Lee, Dong-Kyu Kim. Methodology: Dong-Kyu Kim. Project administration: Dong-Kyu Kim. Resources: Dong-Kyu Kim. Software: Dong-Kyu Kim. Supervision: Dong-Kyu Kim. Validation: Dong-Kyu Kim. Visualization: Kang Hyun Lee, Dong-Kyu Kim. Writing - original draft: Kang Hyun Lee, Dong-Kyu Kim. Writing - review \& editing: Dong-Kyu Kim. 


\section{ORCID}

Dong-Kyu Kim https://orcid.org/0000-0003-4917-0177

\section{REFERENCES}

1) Heinkel N. Sick building syndrome: What it is and tips for prevention. Occup Health Saf 2016;85(10):62-4.

2) Hoddinott KB, Lee AP. The use of environmental risk assessment methodologies for an indoor air quality investigation. Chemosphere 2000;41(1-2):77-84.

3) Ofungwu J. Indoor air quality investigation and health risk assessment at correctional institutions. Integr Environ Assess Manag 2005;1(2):135-41.

4) Han C, Kim S, Lim YH, Bae HJ, Hong YC. Spatial and temporal trends of number of deaths attributable to ambient PM2.5 in the Korea. J Korean Med Sci 2018;33(30):e193.

5) Lim SS, Vos T, Flaxman AD, Danaei G, Shibuya K, Adair-Rohani $\mathrm{H}$, et al. A comparative risk assessment of burden of disease and injury attributable to 67 risk factors and risk factor clusters in 21 regions, 1990-2010: A systematic analysis for the Global Burden of Disease Study 2010. Lancet 2012;380(9859):2224-60.

6) Cohen AJ, Brauer M, Burnett R, Anderson HR, Frostad J, Estep K, et al. Estimates and 25-year trends of the global burden of disease attributable to ambient air pollution: An analysis of data from the Global Burden of Diseases Study 2015. Lancet 2017;389(10082): 1907-18.

7) Chang M, Lee D, Park H, Ha M, Hong YC, Kim Y, et al. Prenatal TVOCs exposure negatively influences postnatal neurobehavioral development. Sci Total Environ 2018;618:977-81.

8) Syazwan A, Rafee BM, Hafizan J, Azman A, Nizar A, Izwyn Z, et al. Development of an indoor air quality checklist for risk assessment of indoor air pollutants by semiquantitative score in nonindustrial workplaces. Risk Manag Healthc Policy 2012;5:17-23.

9) Hwang $\mathrm{SH}$, Park WM. Indoor air concentrations of carbon dioxide $\left(\mathrm{CO}_{2}\right)$, nitrogen dioxide $\left(\mathrm{NO}_{2}\right)$, and ozone $\left(\mathrm{O}_{3}\right)$ in multiple healthcare facilities. Environ Geochem Health 2020;42(5):1487-96.

10) Lee K, Choi JH, Lee S, Park HJ, Oh YJ, Kim GB, et al. Indoor levels of volatile organic compounds and formaldehyde from emission sources at elderly care centers in Korea. PLoS One 2018;13(6):e0197495.

11) Park JS, Ikeda K. Variations of formaldehyde and VOC levels during 3 years in new and older homes. Indoor Air 2006;16(2):12935 .

12) Bang CS, Lee K, Yang YJ, Baik GH. Ambient air pollution in gastrointestinal endoscopy unit. Surg Endosc 2019.

13) Bang CS, Lee K, Choi JH, Soh JS, Hong JY, Baik GH, et al. Ambient air pollution in gastrointestinal endoscopy unit; rationale and design of a prospective study. Medicine (Baltimore) 2018;97(49):e13600.

14) Osman LM, Douglas JG, Garden C, Reglitz K, Lyon J, Gordon S, et al. Indoor air quality in homes of patients with chronic obstructive pulmonary disease. Am J Respir Crit Care Med 2007;176(5):465-72.

15) Cincinelli A, Martellini T. Indoor air quality and health. Int J Environ Res Public Health 2017;14(11):1286.

16) Pitarma R, Marques G, Ferreira BR. Monitoring indoor air quality for enhanced occupational health. J Med Syst 2017;41(2):23.

17) Monn C, Becker S. Cytotoxicity and induction of proinflammatory cytokines from human monocytes exposed to fine (PM2.5) and coarse particles (PM10-2.5) in outdoor and indoor air. Toxicol Appl Pharmacol 1999;155(3):245-52.

18) Kado NY, Colome SD, Kleinman MT, Hsieh DP, Jaques P. Indooroutdoor concentrations and correlations of PM10-associated mutagenic activity in nonsmokers' and asthmatics' homes. Environ Sci Technol 1994;28(6):1073-8.

19) Xu J, Bai Z, You Y, Zhou J, Zhang J, Niu C, et al. Residential indoor and personal PM10 exposures of ambient origin based on chemical components. J Expo Sci Environ Epidemiol 2014;24(4):428-36.

20) Azuma K, Kagi N, Yanagi U, Osawa H. Effects of low-level inhalation exposure to carbon dioxide in indoor environments: A short review on human health and psychomotor performance. Environ Int 2018;121(Pt 1):51-6.

21) Myatt TA, Staudenmayer J, Adams K, Walters M, Rudnick SN, Milton DK. A study of indoor carbon dioxide levels and sick leave among office workers. Environ Health 2002;1(1):3.

22) Mitteilungen der Ad-hoc-Arbeitsgruppe Innenraumrichtwerte der Innenraumlufthygiene-Kommission des Umweltbundesamtes und der Obersten Landesgesundheitsbehörden. [Health evaluation of carbon dioxide in indoor air]. Bundesgesundheitsblatt Gesundheitsforschung Gesundheitsschutz 2008;51(11):1358-69.

23) Otto DA. Assessment of neurobehavioral response in humans to low-level volatile organic compound sources. Ann N Y Acad Sci 1992;641:248-60.

24) Kang J, Liu J, Pei J. The indoor volatile organic compound (VOC) characteristics and source identification in a new university campus in Tianjin, China. J Air Waste Manag Assoc 2017;67(6): 725-37.

25) Scahill J, Wolfrum EJ, Michener WE, Bergmann M, Blake DM, Watt AS. A new method for the rapid determination of volatile organic compound breakthrough times for a sorbent at concentrations relevant to indoor air quality. J Air Waste Manag Assoc 2004;54(1):105-10.

26) Sparks LE, Guo Z, Chang JC, Tichenor BA. Volatile organic compound emissions from latex paint--Part 2. Test house studies and indoor air quality (IAQ) modeling. Indoor Air 1999;9(1):18-25.

27) Alberts WM. Indoor air pollution: $\mathrm{NO}, \mathrm{NO}_{2}, \mathrm{CO}$, and $\mathrm{CO}_{2} . \mathrm{J}$ Allergy Clin Immunol 1994;94(2 Pt 2):289-95.

28) Arbex MA, Martins LC, Pereira LA, Negrini F, Cardoso AA, Melchert WR, et al. Indoor $\mathrm{NO}_{2}$ air pollution and lung function of professional cooks. Braz J Med Biol Res 2007;40(4):527-34. 